\title{
Laryngoplastyka iniekcyjna jako metoda leczenia zaburzeń głosu w wieku senioralnym
}

\section{Injection laryngoplasty as a treatment method of age-related dysphonia}

\author{
Beata Miaśkiewicz ${ }^{1}$, Agata Szkiełkowska ${ }^{1,2}$ \\ ${ }^{1}$ Instytut Fizjologii i Patologii Słuchu, Światowe Centrum Słuchu, Warszawa/Kajetany \\ ${ }^{2}$ Uniwersytet Muzyczny Fryderyka Chopina, Katedra Audiologii i Foniatrii, Warszawa
}

Adres autora: Beata Miaśkiewicz, Światowe Centrum Słuchu, ul. Mokra. 17, Kajetany, 05-830 Nadarzyn, e-mail: b.miaskiewicz@ifps.org.pl

\section{Streszczenie}

\begin{abstract}
Wprowadzenie: Presbyfonia jest globalnym procesem obejmującym wszystkie struktury traktu głosowego. Fizjologiczne starzenie się narządu głosu prowadzi do atrofii fałdów głosowych, degeneracji struktury warstwowej lamina propria, do zmian w obrębie stawu pierścienno-nalewkowego, co skutkuje niewydolnością fonacyjną głośni.
\end{abstract}

Cel: Celem pracy była analiza jakości głosu po zabiegu laryngoplastyki iniekcyjnej u osób w wieku senioralnym.

Materiał i metody: Materiał pracy stanowiła grupa 26 osób w wieku od 60 do 81 lat (średnia wieku 71,5 lat) z presbyfonią, u których wykonano zabieg laryngoplastyki iniekcyjnej. U wszystkich osób wykonano badanie laryngologiczno-foniatryczne, obejmujące laryngovideostroboskopię (LVS), ocenę percepcyjną i akustyczną głosu. U wszystkich badanych przeprowadzono laryngoplastykę iniekcyjną z użyciem kwasu hialuronowego Badania kontrolne były wykonywane 6 miesięcy po augmentacji.

Wyniki: W pooperacyjnym badaniu stroboskopowym zaobserwowano u wszystkich chorych częściowe lub całkowite zamknięcie szpary fonacyjnej. Ocena głosu w skali GRBAS wykazała poprawę jakości głosu po zabiegu. W analizie MDVP zaobserwowano zmniejszenie wartości wszystkich ocenianych parametrów amplitudowych oraz parametru Jitt i SPI, jednak nie były to różnice istotne statystycznie.

Wnioski: Laryngoplastyka iniekcyjna jest skuteczną metodą poprawy głosu u pacjentów z presbyfonią.

Słowa kluczowe: presbyphonia • presbylaryngis $\bullet$ injection laryngoplasty $\bullet$ glottal insufficiency

Abstract

Introduction: Presbyphonia is the physiological process of aging voice that leads to atrophy of the vocal folds, morphological changes in the coverage mucosa, muscles, and cartilages.

Aim: To assess the quality of voice after injection laryngoplasty.

Material and methods: The material included 26 patients with presbyphonia (60-81 y.o.). Preoperative and postoperative examination included laryngovideostroboscopy (LVS), perceptual voice assessment (GRBAS), objective acoustic analysis (MDVP). Patients underwent injection laryngoplasty. Follow-up examinations were conducted 6 months postoperatively.

Results: The postoperative LVS examination showed that in all cases the phonatory gap was partially or totally closed. Perceptual voice quality (GRBAS) was improved and the results were stable in the follow up periods. MDVP showed a significant statistical improvement within the group of amplitude (APQ, Shim, vAm) and frequency parameters (Jita); other studied parameters did not change significantly, although their values decreased after surgery. The differences in value between followup periods were not statistically significant. 
Conclusions: Injection laryngoplasty is the fast method of rehabilitation of phonatory function and restoration of voice in older people.

Key words: presbyphonia $\bullet$ presbylaryngis $\bullet$ injection laryngoplasty $\bullet$ glottal insufficiency

\section{Wstęp}

Liczba osób powyżej 65 roku życia rośnie systematycznie z roku na rok. Wraz ze wzrostem tej części populacji zwiększa się odsetek osób, które pozostają aktywne zawodowo. Jest to przyczyną narastania problemów głosowych w tej grupie wiekowej, które skłaniają do wizyty u lekarza foniatry[1]. Jak szacują Amerykanie, 29\% osób w wieku senioralnym zgłasza zaburzenia głosu, ale jedynie 15-20\% szuka pomocy medycznej z tego powodu [2].

Pacjenci skarżą się najczęściej na zmniejszenie natężenia głosu, przewlekłą chrypkę, szorstkość w głosie, obniżenie wysokości głosu u kobiet a podwyższenie u mężczyzn, zwiększony wysiłek podczas tworzenia głosu [3]. Zmiany morfologiczno-czynnościowe w krtani w presbyfonii obejmują ścieńczenie powierzchownej i środkowej warstwy blaszki właściwej (lamina propria), co prowadzi do atrofii fałdów głosowych, uwydatnienia wyrostków głosowych i wklęśnięcia wolnych brzegów fałdów głosowych oraz powstania niewydolności głośni, co częściej obserwujemy u mężczyzn. Dochodzi do wydłużenia fazy otwarcia cyklu głośniowego, zwiększenia amplitudy drgań, degeneracji szkieletu chrzęstnego krtani oraz połączeń stawowych $[1,2,4]$. Niemałe znaczenie ma rozwinięcie się wtórnych mechanizmów kompensacyjnych, które zaburzają prawidłowy wzorzec emisji głosu.

Proces starzenia głosu obejmuje nie tylko zmiany w obrębie krtani. Istotny wpływ na jakość głosu ma zaburzenie sprawnego funkcjonowania układu oddechowego, w szczególności zmniejszenie pojemności życiowej i zwiększenie objętości zalegającego powietrza w płucach, usztywnienie klatki piersiowej oraz zmniejszenie elastyczności płuc. Nie bez znaczenia są inwolucyjne zmiany w układzie endokrynnym czy ośrodkowym układzie nerwowym [5].

W literaturze wymienia się terapię głosową, laryngoplastykę iniekcyjną oraz tyreoplastykę medializacyjną, jako aktualnie stosowane metody leczenia w presbyfonii [6].

\section{Materiał i metody}

\section{Materiał}

Materiał pracy stanowiła grupa 26 osób w wieku od 60 do 81 lat (średnia wieku 71,5 lat), u których rozpoznano zaburzenia głosu o charakterze presbyfonii. Chorzy zgłaszali osłabienie i łatwą męczliwość głosu, przewlekłą chrypkę o zmiennym nasileniu, czasami zanikanie głosu oraz jego podwyższenie zauważalne głównie u mężczyzn. W grupie badawczej znajdowało się 19 mężczyzn i 7 kobiet. Wszyscy chorzy byli leczeni chirurgicznie metodą laryngoplastyki iniekcyjnej w Instytucie Fizjologii i Patologii Słuchu w Warszawie w latach 2010-2015.

\section{Metody}

U wszystkich osób wykonano badanie laryngologiczno-foniatryczne, obejmujące laryngovideostroboskopię (LVS), ocenę percepcyjną i akustyczną głosu oraz subiektywną ocenę głosu przez pacjenta $z$ wykorzystaniem ankiety Voice Handicap Index. Badania były wykonywane przed zabiegiem oraz 6 miesięcy po operacji fonochirurgicznej. Ocenę LVS krtani przeprowadzono przy użyciu aparatury EndoStrob DX Xion 327. W badaniu oceniano stopień zwarcia fałdów głosowych podczas fonacji, obecność cech atrofii fałdu głosowego oraz kompresji nadgłośniowej.

Do oceny głosu pacjentów zastosowano opisaną przez Hirano w 1981 roku skalę Japońskiego Towarzystwa Logopedów i Foniatrów - GRBAS. W metodzie tej oceniano w skali od 0 do 3: stopień chrypki - G (grade), szorstkość głosu - R (roughness), głos o charakterze chuchającym B (breathiness), głos słaby - A (asthenic) oraz głos napięty $-\mathrm{S}$ (strained).

Obiektywną akustyczną ocenę głosu z wykorzystaniem programu MDVP (Multidimensional Voice Program), przeprowadzono przy użyciu aparatury firmy KAY CSL. Do badań wykorzystano samogłoskę „a” o przedłużonej fonacji, którą zarejestrowano przy użyciu mikrofonu pojemnościowego AKG cechowanego przez firmę KAY. Analizie poddano wybrane parametry określające cechy fizyczne głosu: parametry oceniające względną zmianę częstotliwości (Jita, Jitt, APQ, PPQ, sPPQ, vFo, Fo), parametry oceniające względną zmianę amplitudy (ShdB, Shim, APQ, sAPQ, vAm) oraz parametry względnych pomiarów hałasu (NHR, SPI).

U wszystkich pacjentów zastosowano przedoperacyjną rehabilitację głosu, która obejmowała spotkania jeden raz w tygodniu przez okres 2-3 miesięcy. Jej celem była eliminacja niekorzystnych nawyków emisyjnych, poprzez poprawę koordynacji oddechowo-fonacyjnej, wydłużenie fazy wydechowej czy zmniejszenie kompresji nadgłośniowej. $\mathrm{Z}$ uwagi na brak zadowalających efektów, chorych $\mathrm{z}$ badanej grupy zakwalifikowano do laryngoplastyki iniekcyjnej w znieczuleniu ogólnym z zastosowaniem kwasu hialuronowego (Surgiderm 24XP, Allergan). Preparat kwasu hialuronowego w ilości 0,2-0,5 ml/fałd głosowy, wstrzykiwano obustronnie jak najbliżej głębokiej warstwy blaszki właściwej fałdu głosowego w punktach położonych ku przodowi od wyrostka głosowego oraz w połowie długości fałdu, aby uzyskać wyrównanie wolnego brzegu fałdu. Celem zabiegu było przywrócenie właściwych warunków do tworzenia dźwięcznego głosu na poziomie głośni poprzez poprawę zwarcia fonacyjnego. U 16 osób z badanej grupy, $\mathrm{z}$ uwagi na utrzymywanie się po zabiegu niekorzystnych mechanizmów kompensacyjnych, w okresie do 6 miesięcy po augmentacji wdrożono rehabilitację głosu. Do subiektywnej oceny głosu przez pacjenta wykorzystano Wskaźnik Niepełnosprawności Głosu (VHI-Voice Handicap Index) [7]. Pełne wyniki ankiety otrzymano tylko od 11 osób. 
Tabela 1. Wyniki percepcyjnej oceny głosu w skali GRBAS w badanej grupie pacjentów przed i po leczeniu chirurgicznym Table 1. Results of perceptual voice assessment in GRBAS scale in the studied group before and after surgical treatment

\begin{tabular}{|c|c|c|c|c|c|}
\hline \multirow{2}{*}{$\begin{array}{l}\text { Cecha skali } \\
\text { GRBAS }\end{array}$} & \multicolumn{2}{|c|}{ Przed zabiegiem } & \multicolumn{2}{|c|}{ Po zabiegu } & \multirow{2}{*}{ Poziom p } \\
\hline & Średnia & $\begin{array}{l}\text { Odchylenie } \\
\text { standardowe }\end{array}$ & Średnia & $\begin{array}{l}\text { Odchylenie } \\
\text { standardowe }\end{array}$ & \\
\hline G & 1,44 & 0,70 & 1,00 & 0,43 & 0,1159 \\
\hline $\mathrm{R}$ & 1,72 & 0,67 & 1,00 & 0,60 & 0,0180 \\
\hline$B$ & 1,44 & 0,62 & 0,67 & 0,49 & 0,0145 \\
\hline A & 1,06 & 0,87 & 0,25 & 0,45 & 0,0300 \\
\hline S & 1,06 & 1,00 & 0,58 & 0,67 & 0,0277 \\
\hline
\end{tabular}

Uzyskane wyniki badań głosów pacjentów, z wyjątkiem VHI (zbyt mała liczba osób), poddano analizie statystycznej, którą przeprowadzono z wykorzystaniem testu kolejności par Wilcoxona. Za wartości istotne statystycznie przyjęto wartość współczynnika p na poziomie 0,05 .

\section{Cel}

Celem pracy była analiza jakości głosu po zabiegu augmentacji kwasu hialuronowego u osób w wieku senioralnym.

\section{Wyniki}

U wszystkich pacjentów w badanym materiale w przedoperacyjnym badaniu LVS stwierdzono owalną szczelinę fonacyjną oraz wklęśnięcie wolnych brzegów fałdów głosowych z cechami atrofii, co było podstawowym kryterium kwalifikującym do laryngoplastyki iniekcyjnej. Po augmentacji pełne zwarcie fonacyjne uzyskano u 17 osób. W pozostałych 9 przypadkach zaobserwowano zmniejszenie owalnej szczeliny fonacyjnej.

W następstwie leczenia chirurgicznego odnotowano lepszą jakość głosu ocenianego w skali percepcyjnej GRBAS oraz obiektywnym badaniu MDVP (Tabela 1). W badaniach wykonanych 6 miesięcy po augmentacji zaobserwowano poprawę w zakresie większości parametrów skali GRBAS. Stwierdzono istotne statystycznie zmniejszenie szorstkości w głosie $-\mathrm{R}(\mathrm{p}=0,0180)$, stopnia przydechu $-\mathrm{B}$ $(\mathrm{p}=0,0145)$, osłabienia głosu $-\mathrm{A}(\mathrm{p}=0,0300)$ oraz napięcia $\mathrm{w}$ głosie $-\mathrm{S}(\mathrm{p}=0,0277)$. Jedynie nasilenie stopnia chrypki (G) zmniejszyło się nieistotnie $(\mathrm{p}=0,1159)$

W wieloparametrycznej analizie akustycznej głosu zaobserwowano zmniejszenie wartości wszystkich analizowanych parametrów amplitudowych, jednak różnice te nie były istotne statystycznie (Tabela 2 ). W grupie parametrów częstotliwościowych uzyskano jedynie zmniejszenie wartości Jitt ( $p>0,05)$.Zaobserwowano również obniżenie średniej częstotliwości podstawowej z 183,43 Hz do 165,41 $\mathrm{Hz}(\mathrm{p}=0,133)$ oraz SPI $(\mathrm{p}=0,1961)$.

Na podstawie wyników ankiety VHI odnotowano poprawę jakości głosu w odczuciu pacjentów i zmniejszenie skali niepełnosprawności z dużego do średniego stopnia. Średnia wartość VHI przed zabiegiem wynosiła 61 (zakres 26-89), natomiast 6 miesięcy po augmentacji wyniosła
39 (zakres 0-57). Zmniejszenie średnich wartości punktowych było szczególnie widoczne dla oceny stanu funkcjonalnego i fizycznego w odniesieniu do głosu.

\section{Dyskusja}

Zwiększający się w populacji odsetek osób po 65 roku życia aktywnych zawodowo może spowodować, że zaburzenia głosu staną się istotnym problemem szczególnie dla profesjonalistów głosowych, jak również dla osób wykorzystujących głos w swojej codziennej pracy. Starzenie się głosu jest naturalnym, fizjologicznym procesem, obejmującym zmiany anatomiczne, hormonalne, układu krążenia, kostnego i nerwowo-mięśniowego, które powodują spodziewane zaburzenia jakości głosu.

Chociaż duży odsetek osób z presbyfonią szuka pomocy medycznej, dla wielu z nich satysfakcjonujące jest zapewnienie, że ich problem z głosem jest wynikiem naturalnego procesu starzenia się organizmu [2] Jednak ponad 50\% decyduje się na różne formy terapii [1]. Laryngoplastyka iniekcyjna, stworzona początkowo dla poprawy zwarcia fonacyjnego w porażeniu fałdu głosowego, jest coraz częściej również stosowana $\mathrm{w}$ leczeniu uwarunkowanych wiekiem zmian w krtani. Z powodu swoich właściwości, spośród wielu materiałów augmentacyjnych, wykorzystywany jest kwas hialuronowy w celu przywrócenia objętości (kształtu) fałdów głosowych, wypełnienia blizn, czy utrzymania prawidłowej fali śluzówkowej $[8,9]$. W procesie starzenia narządu głosu dochodzi do zmniejszenia poziomu kwasu hialuronowego, który jest ważnym składnikiem pozakomórkowej macierzy w lamina propria i produkowany jest przez fibroblasty i makrofagi. Odgrywa kluczową rolę w utrzymaniu mechanicznej stabilizacji i elastyczności fałdów głosowych podczas fonacji, w procesach regeneracyjnych, regulacji uwodnienia macierzy, nawilżeniu błony śluzowej, regulacji ciśnienia osmotycznego oraz stanowi barierę przeciw infekcjom. W procesie starzenia się krtani poziom kwasu hialuronowego zmniejsza się prawie o połowę, co wydaje się uzasadniać jego zastosowanie jako materiału iniekcyjnego [10]. Bazując na sześcioletniej własnej obserwacji, wskazującej na znacznie dłuższy niż opisywany w literaturze okres trwania kwasu hialuronowego [11], autorzy zastosowali ten materiał augmentacyjny dla modelowania kształtu szpary głośni. 
Tabela 2. Wyniki wieloparametrycznej analizy akustycznej głosu w badanej grupie pacjentów przed i po leczeniu chirurgicznym

Table 2. Results of multidimensional acoustic voice analysis in the studied group before and after surgical treatment

\begin{tabular}{|c|c|c|c|c|c|}
\hline \multirow{2}{*}{$\begin{array}{l}\text { Parametry } \\
\text { MDVP }\end{array}$} & \multicolumn{2}{|c|}{ Przed zabiegiem } & \multicolumn{2}{|c|}{ Po zabiegu } & \multirow{2}{*}{ Poziom $p$} \\
\hline & Średnia & $\begin{array}{l}\text { Odchylenie } \\
\text { standardowe }\end{array}$ & Średnia & $\begin{array}{l}\text { Odchylenie } \\
\text { standardowe }\end{array}$ & \\
\hline Jita & 149,85 & 105,43 & 161,58 & 91,265 & 0,5067 \\
\hline Jitt & 2,52 & 1,58 & 2,42 & 1,186 & 0,4216 \\
\hline RAP & 1,47 & 0,94 & 2,02 & 2,174 & 0,5525 \\
\hline $\mathrm{PPQ}$ & 1,52 & 0,99 & 1,52 & 0,833 & 0,4216 \\
\hline sPPQ & 1,87 & 0,99 & 2,06 & 1,086 & 0,7537 \\
\hline FO & 183,43 & 43,49 & 165,41 & 53,633 & 0,1330 \\
\hline vFo & 4,58 & 1,77 & 6,34 & 8,734 & 0,6496 \\
\hline ShdB & 0,84 & 0,38 & 0,73 & 0,279 & 0,2213 \\
\hline Shim & 8,96 & 3,87 & 8,33 & 3,141 & 0,5525 \\
\hline APQ & 6,73 & 2,99 & 6,32 & 2,491 & 0,5067 \\
\hline SAPQ & 10,46 & 4,94 & 9,91 & 4,643 & 0,8139 \\
\hline vAm & 28,04 & 12,98 & 23,04 & 9,858 & 0,1520 \\
\hline $\mathrm{NHR}$ & 0,19 & 0,06 & 0,21 & 0,096 & 0,6002 \\
\hline SPI & 14,06 & 5,01 & 12,46 & 5,683 & 0,1961 \\
\hline
\end{tabular}

W badanej grupie pacjentów zaobserwowano poprawę jakości głosu po zastosowanym leczeniu. W skali percepcyjnej GRBAS uzyskano poprawę istotną statystycznie dla parametrów R,B,A i S, z wyjątkiem stopnia chrypki. Z kolei w obiektywnym akustycznym badaniu głosu (MDVP) stwierdzono zmniejszenie wartości niektórych analizowanych parametrów, ale zmiany nie były istotne statystycznie. Poprawę zaobserwowano głównie wśród parametrów oceniających zmiany amplitudy (ShdB, Shim, APQ, sAPQ, vAm), spośród grupy parametrów częstotliwościowych zmniejszeniu uległa jedynie wartość Jitt, niewielką poprawę osiągnięto dla SPI. Jak widać z osiągniętych rezultatów wypełnienie fałdów głosowych i redukcja niedomykalności fonacyjnej głośni nie są wystarczające dla osiągnięcia istotnej statystycznie poprawy analizowanych parametrów. Laryngoplastyka iniekcyjna nie zmieni mikroarchitektury atroficznych fałdów głosowych. Jednak biorąc pod uwagę właściwości kwasu hialuronowego, być może potrzebny jest dłuższy czas obserwacji po zabiegu. Niepełne efekty po augmentacji mogą wynikać także z rozwinięcia się wtórnych mechanizmów kompensacyjnych w postaci kompresji nadgłośniowej ze współfonacją przedsionkową, nadmiernego napięcia mięśni nadgnykowych i podgnykowych powodującym niekorzystne, nadmierne uniesienie krtani czy ze zmian degeneracyjnych w układzie oddechowym prowadzącym m.in. do skrócenia fazy wydechowej. Pacjenci ci wymagają przed-i pooperacyjnej rehabilitacji głosu oraz reedukacji w zakresie emisji, które są bardzo ważnymi elementami całego procesu terapeutycznego. Nierzadko współwystępujący niedosłuch odbiorczy w tej grupie wiekowej zaburza autokontrolę tworzenia głosu. Pomimo tych wszystkich ograniczeń, pacjenci w badanej grupie ocenili swój głos po zabiegu jako lepszy, mocniejszy, bardziej stabilny. Ocenę tę odzwierciedlają wyniki VHI, które wskazują na skuteczność augmentacji, zwłaszcza dla oceny stanu funkcjonalnego i fizycznego pacjentów w odniesieniu do zaburzeń głosu. W badaniu kohortowym Gartner i wsp. w grupie pacjentów leczonych augmentacją poprawę subiektywną (VHI-10) zgłaszało 56\% operowanych, natomiast tylko $17 \%$ spośród osób, u których najpierw przeprowadzono terapię głosu a następnie iniekcję [2]. Davids i wsp. w małej grupie 8 osób leczonych augmentacją z powodu presbyfonii, uzyskał w ocenie VRQOL (Voice-related quality of life) poprawę istotną statystycznie [1].

Obiecującą terapią ukierunkowaną na leczenie zmian atroficznych fałdów głosowych jest terapia regeneracyjna z wykorzystaniem czynników wzrostu fibroblastów (basic Fibroblast Growth Factor - bFGF) i hepatocytów (Hepatocite Growth Factor - HGF) [12,13]. Szczególnie ten ostatni ma wybitne właściwości stymulujące produkcję kwasu hialuronowego oraz supresję kolagenu typu I, choć jak się okazuje aktywność ta jest mniejsza w starszym wieku [14]. Z kolei w badaniach Hirano i wsp. nie potwierdzono wiekowych ograniczeń, jeśli chodzi o wpływ bFGF na migrację, proliferację i mitogenezę fibroblastów, co w konsekwencji powoduje znaczny wzrost ilości fibroblastów w obrębie lamina propria [13]. Szerokie wdrożenie technik chirurgicznych z zastosowaniem biomateriałów regeneracyjnych wymaga dalszych badań klinicznych, wydaje się być jednak godną rozważenia alternatywą dla dotychczasowych nie w pełni skutecznych metod leczenia zmian w obrębie fałdów głosowych uwarunkowanych fizjologicznym procesem starzenia się krtani. 


\section{Wnioski}

- Laryngoplastyka iniekcyjna jest skuteczną metodą poprawy głosu u pacjentów z presbyfonią.

- Metoda pozwala osobom w wieku senioralnym na szybki powrót funkcji komunikatywnych, aktywności zawodowej oraz zapobiega izolacji społecznej.
- Współwystępowanie ogólnoustrojowych zmian związanych z procesem starzenia się organizmu utrudnia uzyskanie pełnych efektów poprawy głosu po zabiegu laryngoplastyki iniekcyjnej.

\section{Piśmiennictwo:}

1. Davids T, Klein A, Johns MM. Current dysphonia trends in patients over the age of 65: is vocal atrophy becoming more prevalent? Laryngoscope, 2012; 122: 332-35.

2. Gartner-Smith J, Rosen C. Treatment success for age-related vocal folds atrophy. Laryngoscope, 2011; 212: 585-89.

3. Tarafder KH, Datta PG, Tariq A. The aging voice. BSMMU J, 2012; 5(1): 83-86.

4. Pontes C, Brasolotto A, Belhau M. Glottic characteristic and voice complaint in the elderly. J Voice, 2005; 19(1): 84-94.

5. Sataloff RT, Rosen DC, Hawkshaw M, Spiegel J. The aging adult voice. J Voice, 1997, 11(2): 156-60.

6. Bradley JP, Hapner E, Johns MM. What is the optimal treatment for presbyphonia? Laryngoscope, 2014; 124: 2439-40.

7. Pruszewicz A, Obrębowski A, Wiskirska-Woźnica B, Wojnowski W. W sprawie kompleksowej oceny głosu - własna modyfikacja testu samooceny niesprawności głosu (Voice Handicap Index). Otolaryngol Pol, 2004; 58(3): 547-49.

8. Szkiełkowska A, Miaśkiewicz B, Remacle M, Skarzyński H. Quality of voice after implantation of hyaluronic acid into the vocal folds-preliminary report. Otolaryngol Pol, 2011; 65(6): $436-42$.
9. Szkiełkowska A, Miaśkiewicz B, Remacle M, Krasnodębska P, Skarżyński H. Quality of voice after injection of hyaluronic acid into the vocal folds. Med Sci Monit, 2013; 17(19): 276-82.

10. Branco A, Rodrigues SA, Fabro AT, Fonseca-Alves CE, Martins RH. Hyaluronic acid behavior in the lamina propria of the larynx with advancing age. Otolaryngol Head Neck Surg, 2014; 151(4): 652-56.

11. Miaśkiewicz B, Szkiełkowska A. Long-term follow up in injection laryngoplasty with hyaluronic acid. Otorynolaryngol 2014; 13(3): 147-54.

12. Ohno T, Hirano S. Treatment of aging vocal folds: novel approaches. Curr Opin Otolaryngol Head Neck Surg, 2014; 22: $472-76$.

13. Hirano S, Bless D, del Rio AM, Connor N, Ford C. Therapeutic potential of growth factors for voice. Laryngoscope, 2004; 114: 2161-67.

14. Graupp M, Kiesler K, Friedrich G, Ainodhofer H, Gruber JH, Kieslinger P i wsp. Vocal fold fibroblast response to growth factor treatment is age dependent: results from an in vitro study. J Voice, 2014; 28(4): 420-23. 